\title{
Collision Avoidance Protocol for Inter Vehicular Communication
}

\author{
Debasish Roy \\ Department of Computer Science, \\ Assam University Silchar-788011, India
}

\author{
Prodipto Das \\ Department of Computer Science, \\ Assam University Silchar-788011, India
}

\begin{abstract}
Vehicle to vehicle communication can give us better results by avoiding the major problems in road like collision of vehicles, better route selection in case of traffic congestion, fuel consumption, suitable selection of parking place etc. This paper presents a protocol to avoid the collision of vehicles. High mobility and fast topology changes are the characteristics of Vehicular Adhoc Networks (VANETs). To establish the real world environment for VANETs, network simulator NS2 is used. Medium Access Control (MAC) Protocol is used to avoid the collision of transmitted data. The Simulation is done using the proposed Vehicular Adhoc On-demand Distance Vector (VAODV) routing protocol, which is a modification of Ad-hoc On-demand Distance Vector (AODV) routing protocol. The proposed VAODV protocol is continuously checks the distance, speed of each vehicle and if it finds that the distance between vehicles is continuously decreasing then in this case it will send a warning textual message to those vehicles that are in accidental situation. Based on this textual information these vehicles will take particular action like vehicle may choose new route if it exists or it may slow down its own speed or it may stop moving by pressing brake. The experimental results are used to find out the performance of VAODV protocol. The performance of VAODV protocol is analyzed with different parameters like end to end delay, throughput, packet delivery ratio, normalized routing load etc.
\end{abstract}

Keywords: ADC; AES; CAP; CFP; CSMA-CA; MAC; ns-2; OTcl; VAODV; VANETs; Wireless Sensor Networks (WSN)

\section{INTRODUCTION}

Wireless Sensor Networks (WSN) consist numbers of sensor nodes and they work together to perform a specific task. In WSN base-stations gather the data from all other sensor devices in the networks. Sensor devices are adequate to sense the physical entities. The sensors are equipped with rechargeable batteries [1]. The sensor nodes are communicated through the wireless medium. In WSN usually, all sensor nodes are not reachable to all other sensor nodes. It is a multi-hop network [2]. Components of sensor devices (Fig. 1) are: a sensing and actuation unit (array or single element), a power unit, a processing unit, a communication unit and other application-dependent units [3] [4].

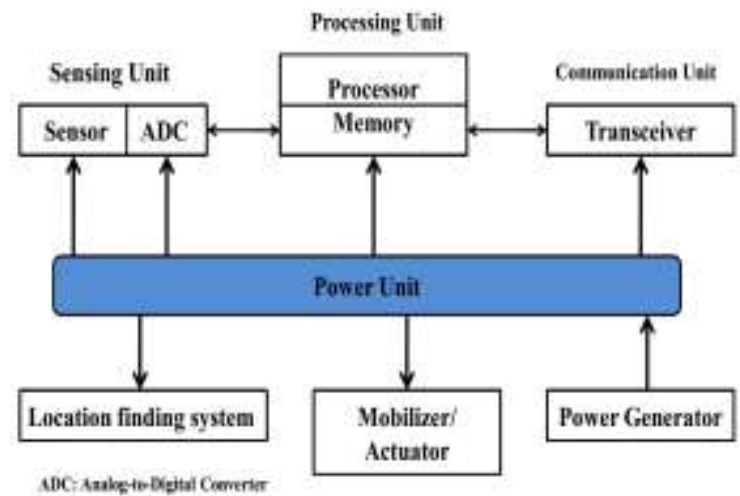

Fig. 1: Components of Sensor Node

Some of the characteristics of wireless sensor networks are topology changes very frequently, sensor devices can join and leave the network at any point of time, sensor devices are having limited power, limited computational capabilities and limited memory, ability to deal with sensor device failure etc.

WSN used in various applications like forest fire detection, flood detection, automated meter reading, vehicle tracking and detection, traffic flow surveillance and many more [4].

\subsection{Vehicular Ad-hoc Network}

VANETs are special type of mobile ad-hoc networks (MANETs). The basic architecture of vehicular network is shown in Fig. 2.

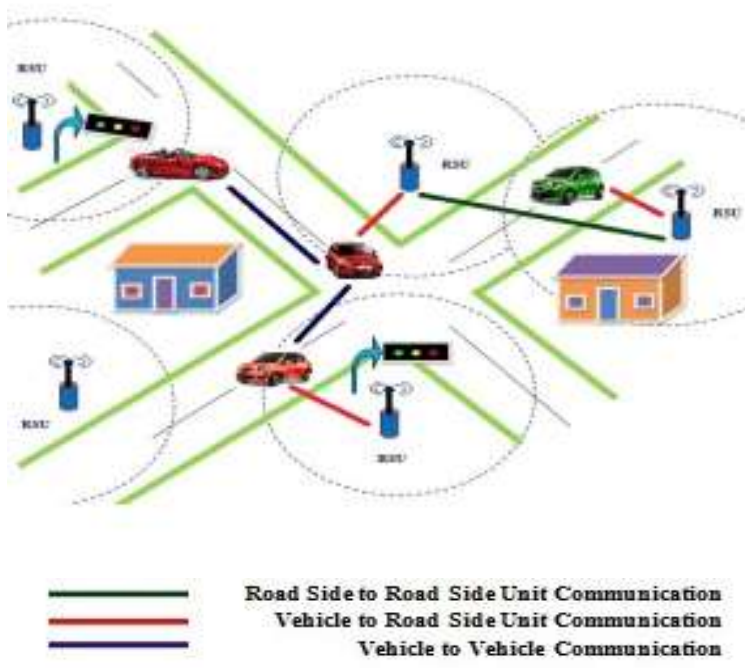

Fig. 2: Vehicular network architecture 
It is a self organizing network which consists of numbers of vehicles. In VANETs, each vehicle is equipped with a device called on-board unit (OBU) which is capable to communicate with other OBUs and road-side units (RSU) using a routing protocol through WSNs. RSU can communicate with the other RSUs. Some RSUs can be used as gateways. Based on these communications VANETs can provide road safety, comfort of driving etc [5] [6] [7].

\subsection{IEEE 802.15.4}

We have used IEEE 802.15.4 standard MAC protocol in our simulation. IEEE 802.15.4 defines the MAC and physical Layers of wireless sensor networks [8]. It is developed for very low power, low cost, moving devices and for short range wireless communications. It gives support to connect devices are in the field of applications like vehicular, industrial, agricultural, residential and medical sensor etc [9]. The standard is pertinent for self-organizing network along with the essence of network flexibility.

The IEEE 802.15.4 standard MAC sub-layers uses the carrier sense multiple access with collision avoidance (CSMA-CA) mechanism for beacon transmission [10]. There are two modes in IEEE 802.15.4 standard: beaconless and the beacon enabled mode. In beaconless mode it uses the pure CSMA-CA for channel access and works as a basic IEEE 802.11 standard without channel reservations. In beacon enabled mode it uses the hybrid time division multiple access (TDMA). In case of time critical transmission it uses guaranteed time slot(GTS) mechanism to reserve a dedicated time slot within a superframe [10] [11]. In a Link-layer security is implemented or designed with 128 bit advanced encryption standard (AES) encryption [11]. In beacon enable mode the source periodically sends beacons for sensor nodes synchronization and to establish the personal area networks (PANs). Each super-frame has two parts active and inactive part. Active part is composed of: a beacon, a contention access period (CAP) and a contention free period (CFP) [12]. IEEE 802.15.4 standard is responsible for acknowledging frame delivery, frame validation, beacon management, GTS management, channel access mechanism, supervise device security etc [13].

\subsection{AODV Routing protocol}

AODV protocol is the advancement of Destination-Sequenced Distance-Vector Routing (DSDV) protocol. AODV is classified as a pure on-demand route acquisition system; nodes do not maintain any routing information or do not exchange any routing table that are not presents in the chosen path[14]. In AODV all the routes are discovered when it is required and are maintained as far as these are being used. Routes are found out through route discovery process. Route discovery starts if a source node required a valid route to some destination node [15].

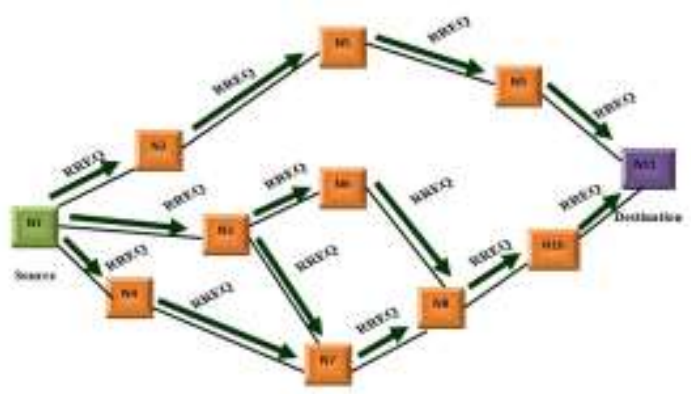

Fig. 3: Route Request Propagation
A route request (RREQ) packet broadcast to all its neighboring nodes by the source node, they again sends the RREQ packet to their neighbors and so on, until destination node found or an intermediate nodes with a route that is fresh enough to reach the destination is found [14] [15] [16]. The propagation of route request is shown in Fig. 3.

AODV utilizes the sequence number that is maintained by all destinations for avoiding routing loops as well as to analyze the newness of routing information [16]. Broadcast ID and node sequence number is maintained by the node itself. For each RREQ made by a node, the Broadcast ID and the IP address are incremented by one for to uniquely identify a RREQ. The source node includes the destination node most recent sequence number and destination IP address, as well as current sequence number of its own and broadcast ID in RREQ [15] [16]. Intermediate node can reply to the RREQ if it has a valid route to reach destination with sequence number greater than or equal to that of the sequence number presents in the RREQ otherwise it rebroadcasts the RREQ [14] [16].

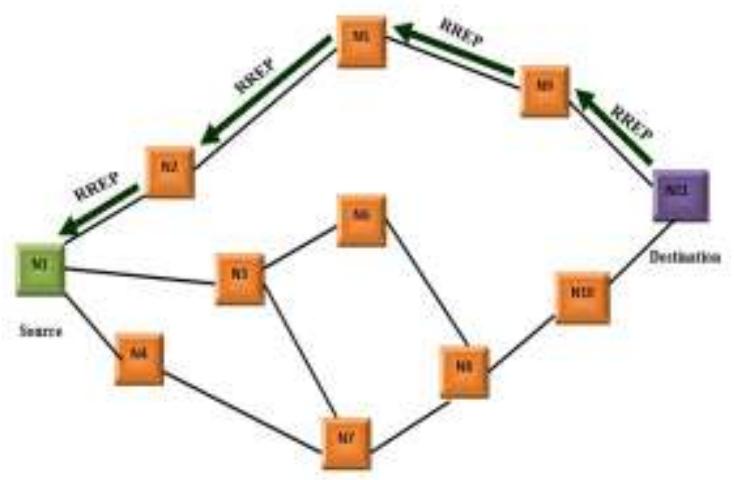

Fig. 4: Route Reply path to the Source

While forwarding the RREQ intermediate nodes record the neighboring node address from where first RREQ packet was received into their own routing table using that information establishes a reverse path to source (Fig. 4). The RREQ packets that are already received if it came later again all these packets are discarded [14] [17]. When the destination gets the RREQ packet or intermediates with fresh enough route, the destination or intermediate replied by unicasting a Route Reply (RREP) control packet back to the neighboring node from which first received the RREQ packet [14] [18]. When the source node received the RREP a complete bidirectional path is establish and the source can start transmission by using this discovered route [14] [16] [17] [18].

\subsection{Network Simulator-2 (NS2)}

We have used NS2 for simulation of vehicular communication. NS2 is the one of the most popular and efficient research simulator for simulation of WSN. It is an open source, object oriented discrete event-driven simulator which is particularly made for to do research in computer networks. NS2 made of two languages: $\mathrm{C}++$ and Objectoriented Tool Command Language (OTcl), where $\mathrm{C}++$ works as backend scheduler and OTcl interpreter as a frontend scheduler. These two languages are interlinked using the Tcl with classes (TclCL). Simulation internals is defined by the $\mathrm{C}++$ whereas OTcl is used for to schedule discrete events and also to control the simulation by the object gathering and configuring. It supports to design a new protocol, protocol comparison, network traffic analysis etc. A simulation is done using three steps which are: simulation design, configure as 
well as to run the simulation and packet tracing which is a text based packet tracing and Network AniMation (NAM) packet tracing [19]. The basic architecture of network simulator is shown in Fig. 5.

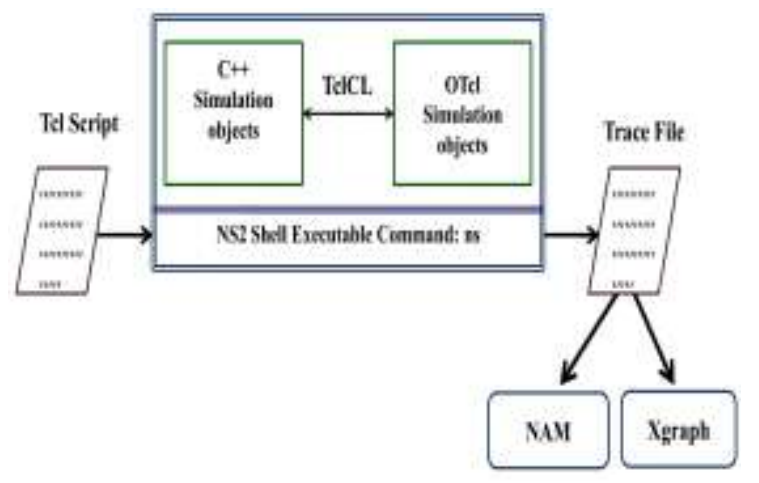

Fig. 5: Basic Network Simulator Architecture

\section{PROPOSED ALGORITHM}

A collision avoidance algorithm for inter vehicular communication:

Step 1:

Find the co-ordinates of vehicles in milliseconds and store results into the variables $\mathrm{X}, \mathrm{Y}$ and $\mathrm{Z}$. That means we are storing the location of vehicles. Here we have assumed that the co-ordinate $\mathrm{Z}$ is always to be Zero because vehicles are not flying.

Step 2:

If after each millisecond co-ordinates of any one of the vehicle is not matched with the previous co-ordinates value of its own then update the value of the variables $\mathrm{X}, \mathrm{Y}$ and $\mathrm{Z}$ for that vehicle, which means we are storing the new location of that Vehicle.

Step 3:

Calculate the Distance (Eq.1) between two vehicles in each millisecond using the formula:

Let $(\mathrm{X} 1, \mathrm{Y} 1)$ be the coordinate of vehicle $\mathrm{A}$ and $(\mathrm{X} 2, \mathrm{Y} 2)$ be the coordinate of vehicle $\mathrm{B}$, then the distance between vehicle $A$ and vehicle $B$ is

Distance $=\sqrt{(X 2-X 1)^{2}+(Y 2-Y 1)^{2}}$

Step 4:

If the distance between vehicles is less than or equal to warning distance then monitoring vehicle will send a textual warning message to the monitored Vehicle.

Step 5:

If the receiver receives the message, then the receiver will take action according to the received textual warning message and will send an acknowledgement message to the sender.

Step 6:

After certain wait if the sender has not got any response from the receiver then repeat Step 4.

\section{IMPLEMENTATION DETAILS}

We have considered four different scenarios for simulation and these are:

\subsection{Scenario One}
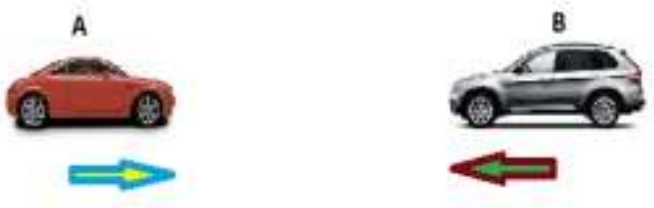

Fig. 6: One source one destination moving towards each other

In this case (Fig. 6), both of the vehicles A and B are moving towards each other at a speed of $100 \mathrm{~km} / \mathrm{h}$. Initially distance between them is 300 meters. Vehicle B is the source node and vehicle $\mathrm{A}$ is the destination node. Vehicle $\mathrm{B}$ is monitoring its distance from vehicle A continuously and the moment it found that the distance monitored is less than or equal to the warning distance it will immediately send a warning textual message to the destination vehicle A. The vehicle A will take action according to the received textual message and gives a response to the sender.

\subsection{Scenario Two}

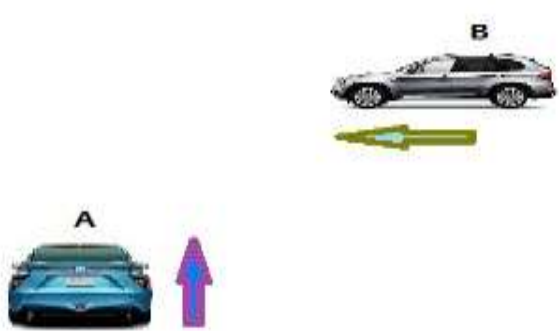

Fig. 7: One source one destination moving in different direction

In this case (Fig. 7), vehicle B is moving towards the west and the vehicle A is moving towards north. Both of the vehicles are moving at a speed of $100 \mathrm{~km} / \mathrm{h}$. Initially distance between them is 212.1320 meters. Vehicle B is the source node and vehicle $\mathrm{A}$ is the destination node. Vehicle $\mathrm{B}$ is monitoring its distance from vehicle A continuously and the moment it found that the distance monitored is less than or equal to the warning distance it will immediately send a warning textual message to the destination vehicle A. The vehicle A will take action according to the received textual message and gives a response to the sender.

\subsection{Scenario Three}
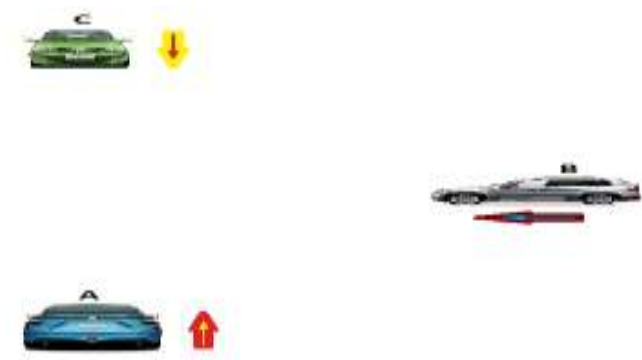

Fig. 8: One source two destinations are moving in different directions 
In this case (Fig. 8), vehicle B is moving towards the west, the vehicle $\mathrm{A}$ is moving towards the north and the vehicle $\mathrm{C}$ is moving towards south. All the three vehicles are moving at speed of $100 \mathrm{~km} / \mathrm{h}$. Initially distance between vehicle B and vehicle $A$ is 212.1320 meters, between vehicle $B$ and vehicle $\mathrm{C}$ is also 212.1320 meters and between vehicle $\mathrm{A}$ and $\mathrm{C}$ is 300 meters. Vehicle B is the source node and vehicle A, vehicle $\mathrm{C}$ are the destination nodes. Vehicle $\mathrm{B}$ is monitoring its distance from vehicle $\mathrm{A}$ and vehicle $\mathrm{C}$ continuously and the moment it found that the distance monitored is less than or equal to the warning distance it will immediately send a warning textual message to the destination vehicle. The destination vehicle will take action according to the received textual message and gives a response to the sender.

\subsection{Scenario Four}
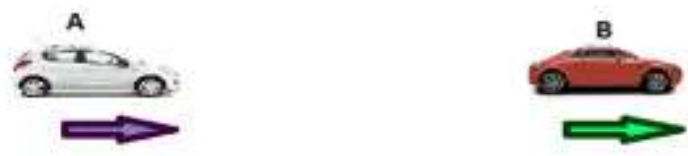

Fig. 9: One source one destination are moving in the same directions

In this case (Fig. 9), vehicle A and vehicle B both are moving in the same direction towards east. Vehicle $\mathrm{A}$ is moving at a speed of $100 \mathrm{~km} / \mathrm{h}$ and the vehicle B is moving at a speed of $70 \mathrm{~km} / \mathrm{h}$. Initially distance between them is 300 meters. Vehicle B is the source node and vehicle A is the destination node. Vehicle B is monitoring its distance from vehicle A continuously and the moment it found that the distance monitored is less than or equal to the warning distance it will immediately send a warning textual message to the destination vehicle A. The vehicle A will take action according to the received textual message and gives a response to the sender.

\subsection{Simulation Configuration}

Simulation environment is configured with the parameters are given in Table 1.

Table 1: VANET Simulation Parameters

\begin{tabular}{|c|c|}
\hline Parameter & Value \\
\hline Routing Protocol & VAODV \\
\hline Channel Type & Wireless Channel \\
\hline Number of Nodes & 2,3 \\
\hline Transport Protocol & UDP \\
\hline Interface Queue Type & Queue/DropTail/PriQueue \\
\hline Queue Length & 50 Packet \\
\hline Data Payload & 512 Bytes/Packet \\
\hline MAC Types & Mac/802_15_4 \\
\hline Mobility & Random way point \\
\hline Transmission Range & 250 meter \\
\hline Speed & $100 \mathrm{~km} / \mathrm{h}, 70 \mathrm{~km} / \mathrm{h}$ \\
\hline Area of Simulation & $8770 \mathrm{~m} \mathrm{X} \mathrm{2738} \mathrm{m}$ \\
\hline Time of Simulation & $40 \mathrm{sec}$ \\
\hline
\end{tabular}

\subsection{Performance Measurement Metrics}

To evaluate the model performance we have used four metrics these are

\section{Average End-to-End delay}

It is the delays due to buffering in the process of route discovery, queuing, delays during MAC level retransmission and the time taken during the propagation and transfer [19] [20]. It can be defined as

Avg_End - to - End_Delay $=\frac{1}{\mathrm{~T}} \sum_{\mathrm{k}=1}^{\mathrm{n}}\left(\mathrm{r}_{\mathrm{k}}-\mathrm{s}_{\mathrm{k}}\right) \quad$ Eq.2

Where $\mathrm{T}$ is the packets that are successfully received, $\mathbf{k}$ is the unique packet identifier, $\mathbf{r}_{\mathbf{k}}$ is the time of the received unique id $\mathrm{k}$ packet and $\mathbf{s}_{\mathbf{k}}$ is the time at which a packet with unique id $\mathrm{k}$ is sent. End-to-End delay is measured in milliseconds.

\section{Normalized Routing Load}

It is the number of routing packets transmitted per data packets delivered at the destinations [19] [20].

Routing Load $=\frac{\text { Routing Packets Sent }}{\text { Data Packets Received }}$

\section{Throughput}

It is the number of bits received per unit time by the destination node. It is represented in kilo bits per seconds (kbps) [19] [20].

Throughput $=\frac{\text { Received Size }}{\text { End Time-Start Time }} \times \frac{\mathrm{g}}{1000}$

Where 'End Time-Start Time' is the data transmission period.

\section{Packet Delivery Ratio}

Ratio of the number of data packets successfully delivered to the destinations to those generated by the sources [19] [20].

Packet Delivery Ratio $=\frac{\text { Receîwed Packets }}{\text { Sent Packets }} \times 100 \% \quad$ Eq. .5

\section{Driver Reaction Time}

Time of the accidental message received and the time of bakes are applied.

Driver Reaction Time $=$ Message Receive Time + 0.75

$0.75 \mathrm{sec}$ is the time taken by the driver to step his foot onto the brake pedal and press the brake [21].

\section{SIMULATION RESULTS, ANALYSIS AND DISCUSSION}

Simulation results are shown in Fig. 10-35 using gnu plot line graph

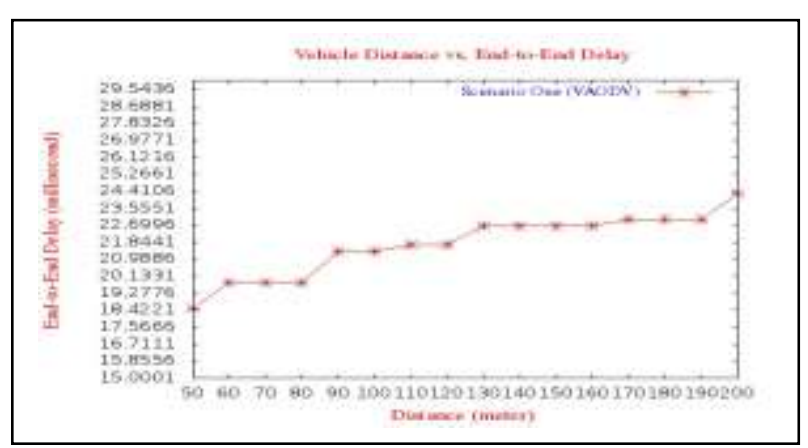

Fig. 10: Distance vs. End-to-End Delay for Scenario One 
International Journal of Computer Applications Technology and Research

Volume 4- Issue 10, 767 - 776, 2015, ISSN: 2319-8656

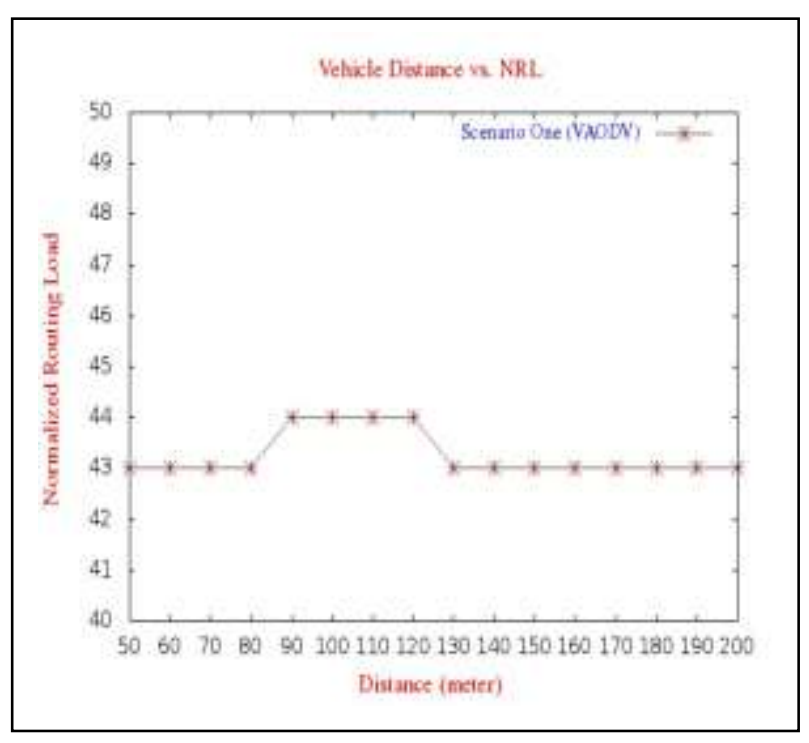

Fig. 11: Vehicle Distance vs. NRL for Scenario One

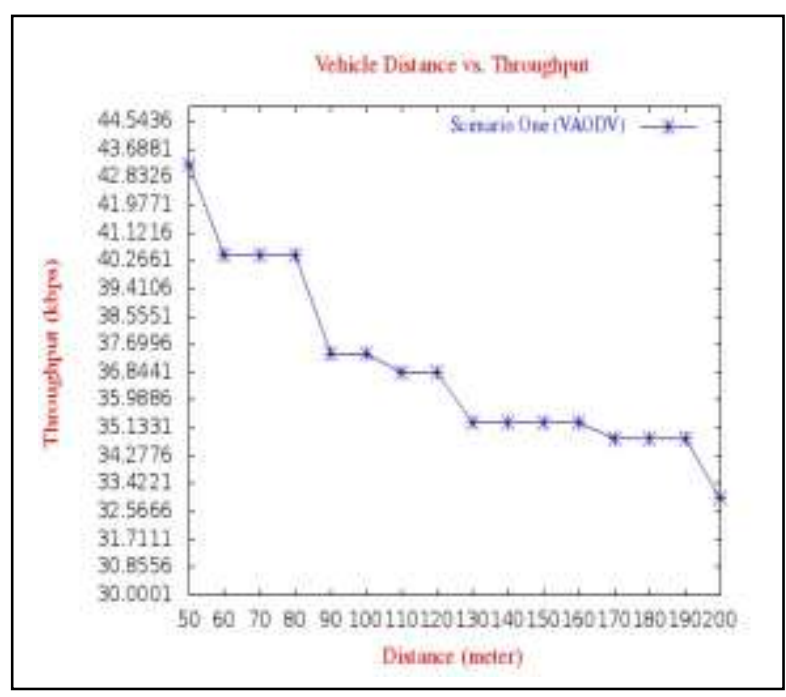

Fig. 12: Vehicle Distance vs. Throughput for Scenario One

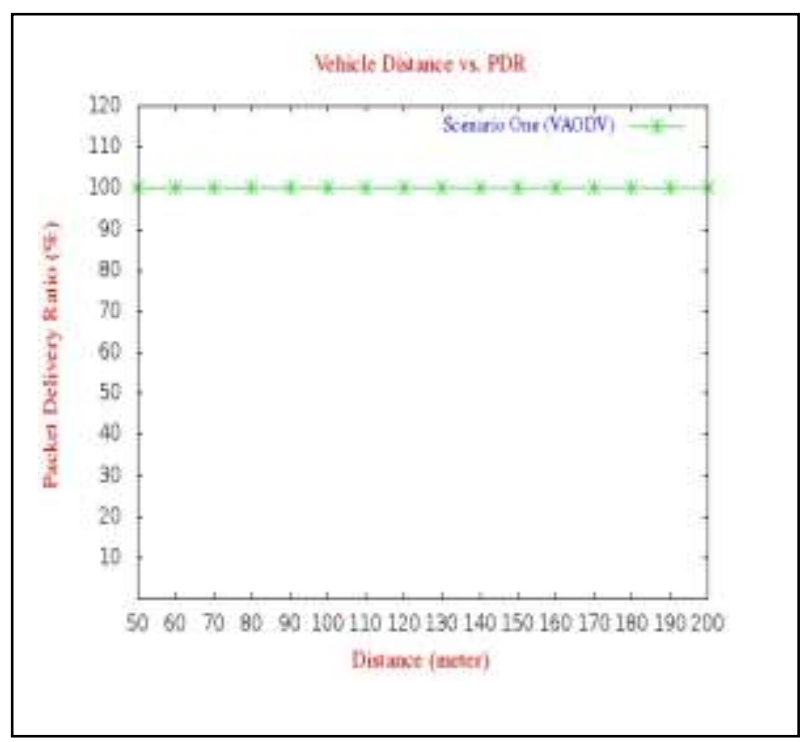

Fig. 13: Vehicle Distance vs. PDR for Scenario One

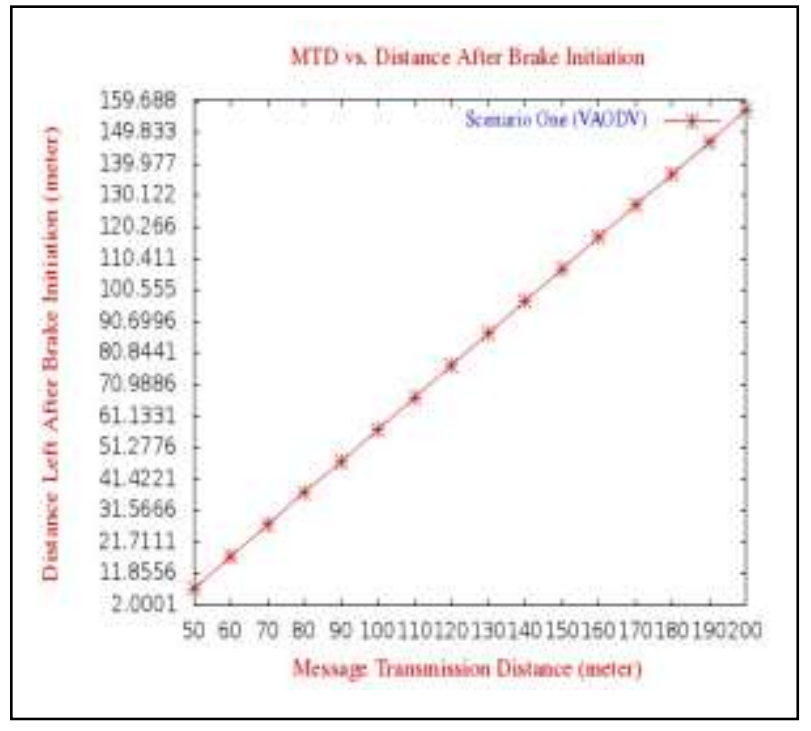

Fig. 14: MTD vs. Distance left for Scenario One

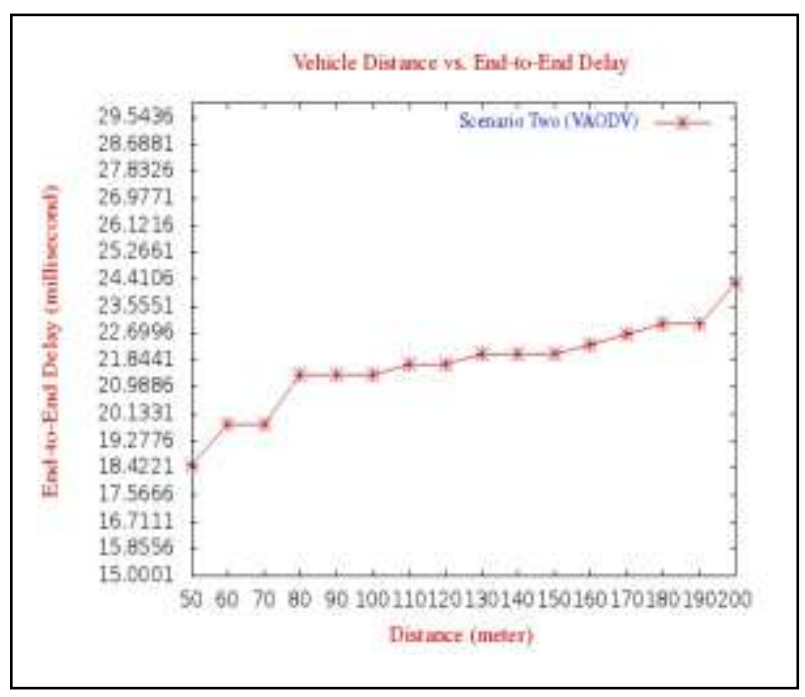

Fig. 15: Distance vs. End-to-End Delay for Scenario Two

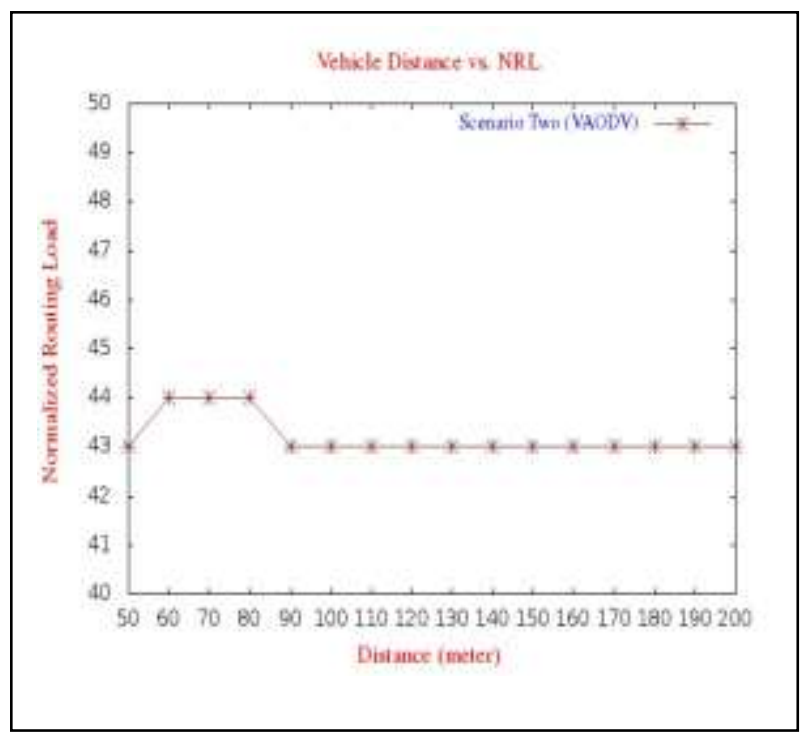

Fig. 16: Vehicle Distance vs. NRL for Scenario Two 
International Journal of Computer Applications Technology and Research

Volume 4- Issue 10, 767 - 776, 2015, ISSN: 2319-8656

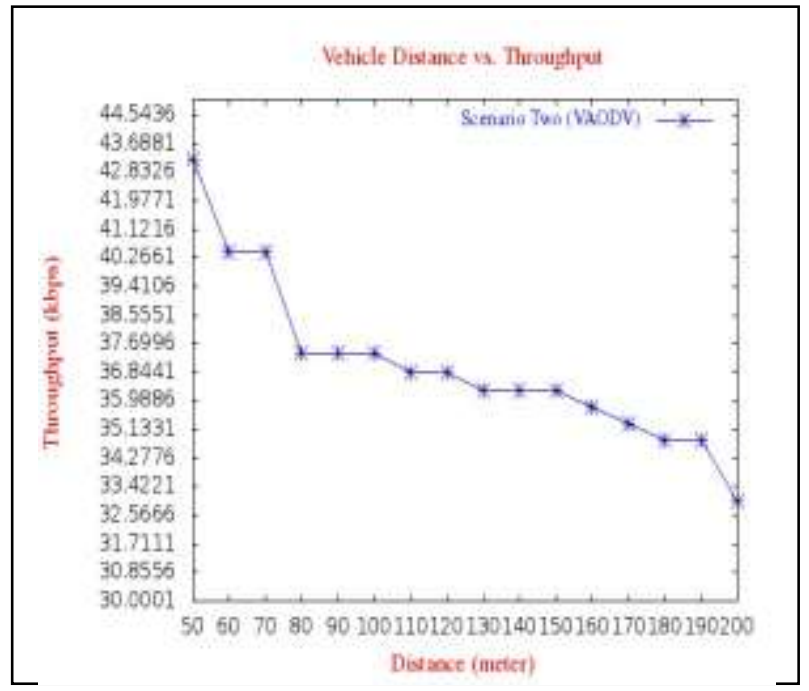

Fig. 17: Vehicle Distance vs. Throughput for Scenario Two

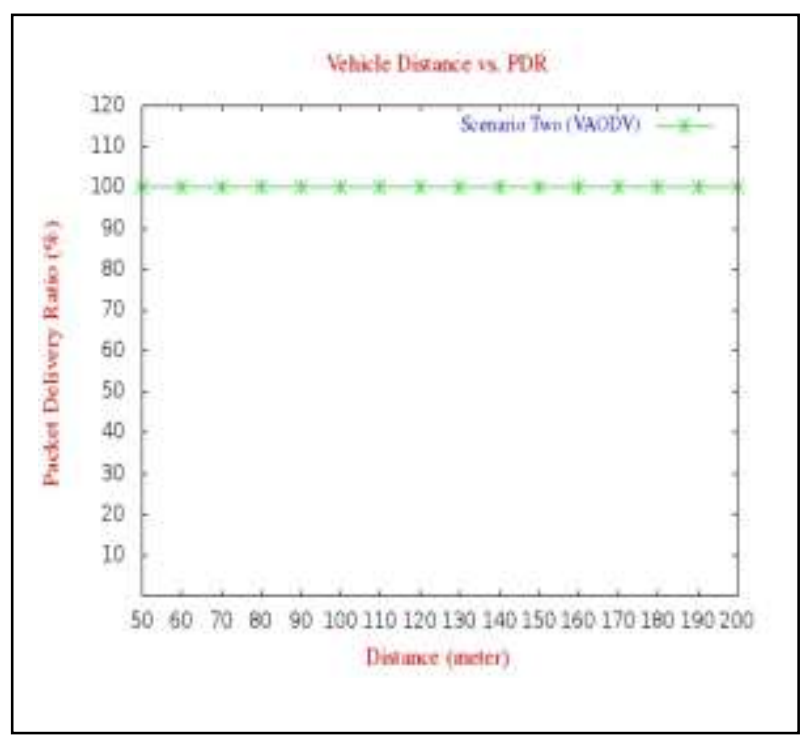

Fig. 18: Vehicle Distance vs. PDR for Scenario Two

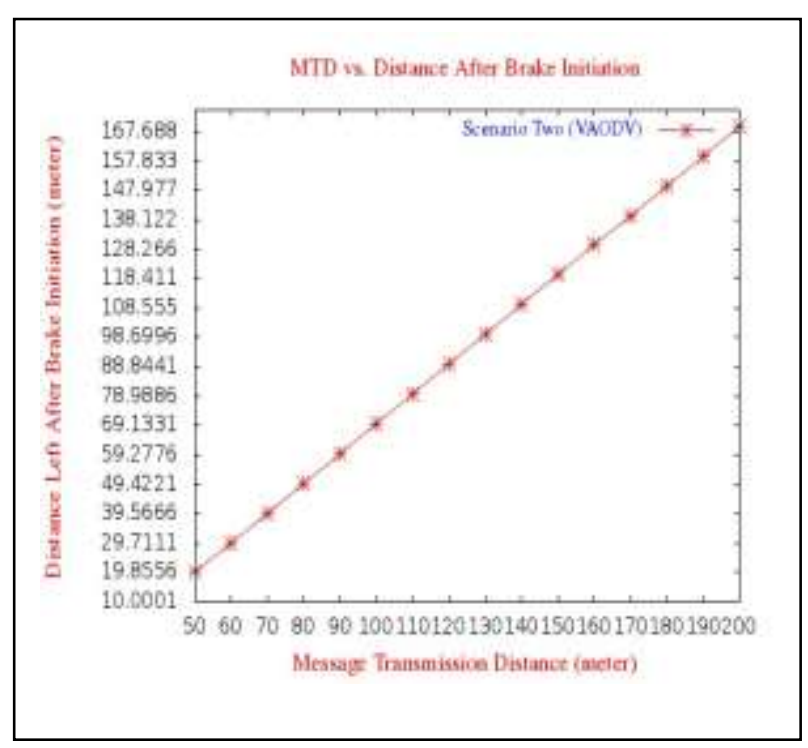

Fig. 19: MTD vs. Distance left for Scenario Two

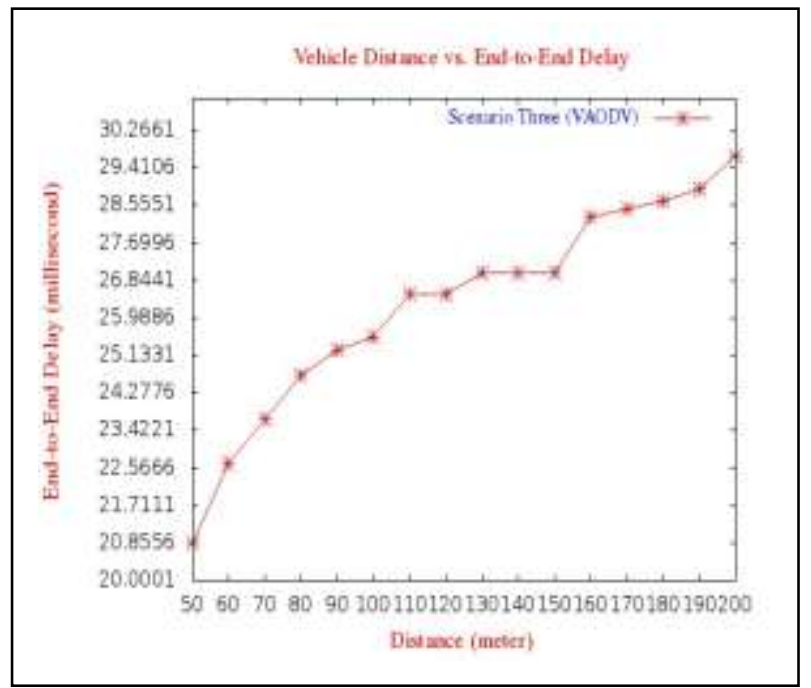

Fig. 20: Distance vs. End-to-End Delay for Scenario Three

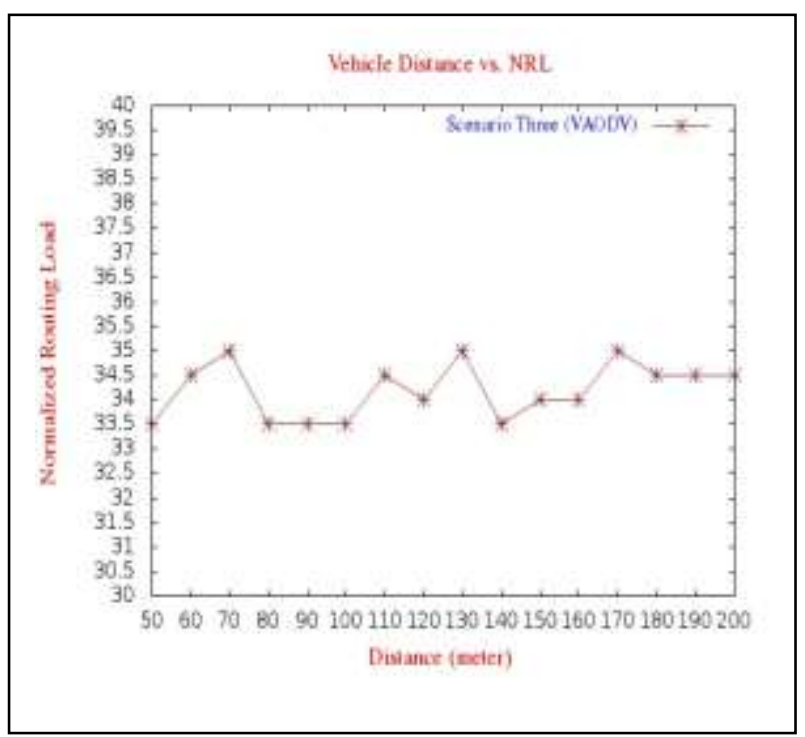

Fig. 21: Vehicle Distance vs. NRL for Scenario Three

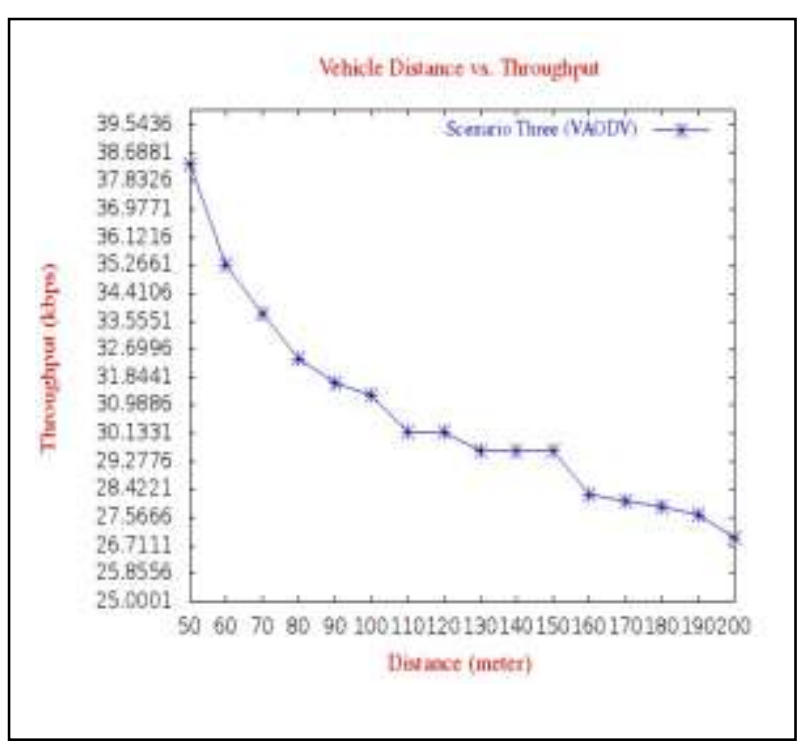

Fig. 22: Distance vs. Throughput for Scenario Three 
International Journal of Computer Applications Technology and Research

Volume 4- Issue 10, 767 - 776, 2015, ISSN: 2319-8656

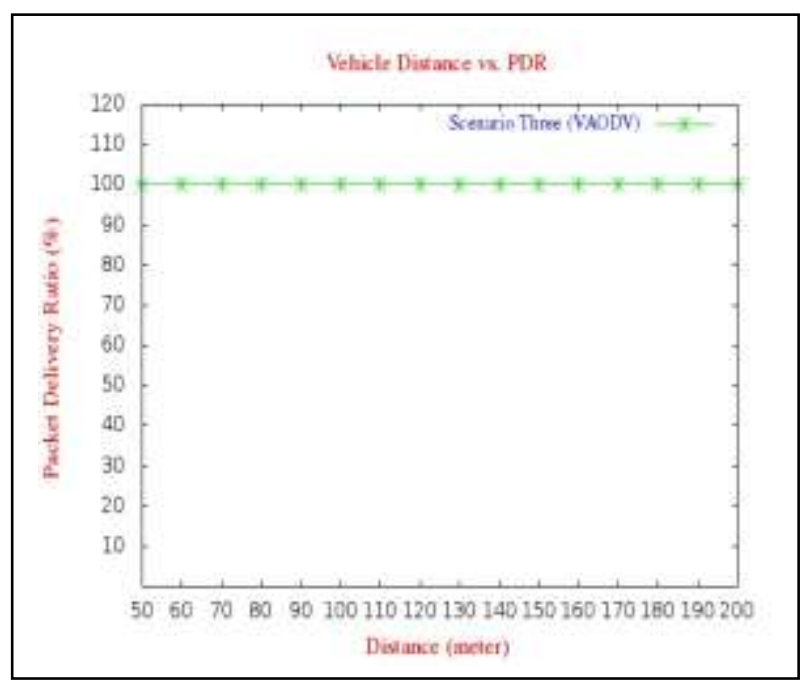

Fig. 23: Vehicle Distance vs. PDR for Scenario Three

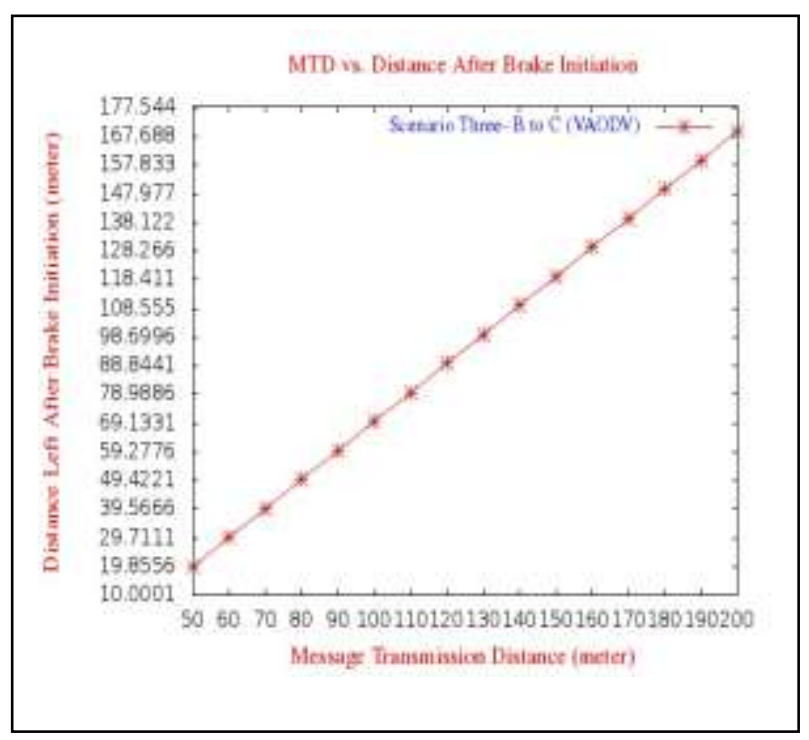

Fig. 24: MTD vs. Distance left in B to C for Scenario Three

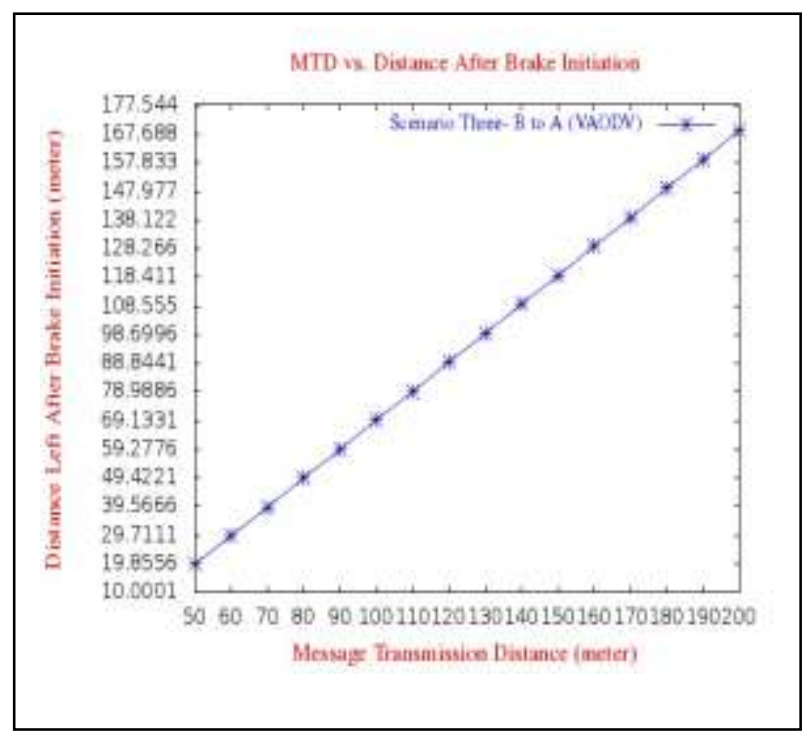

Fig. 25: MTD vs. Distance left in B to A for Scenario Three

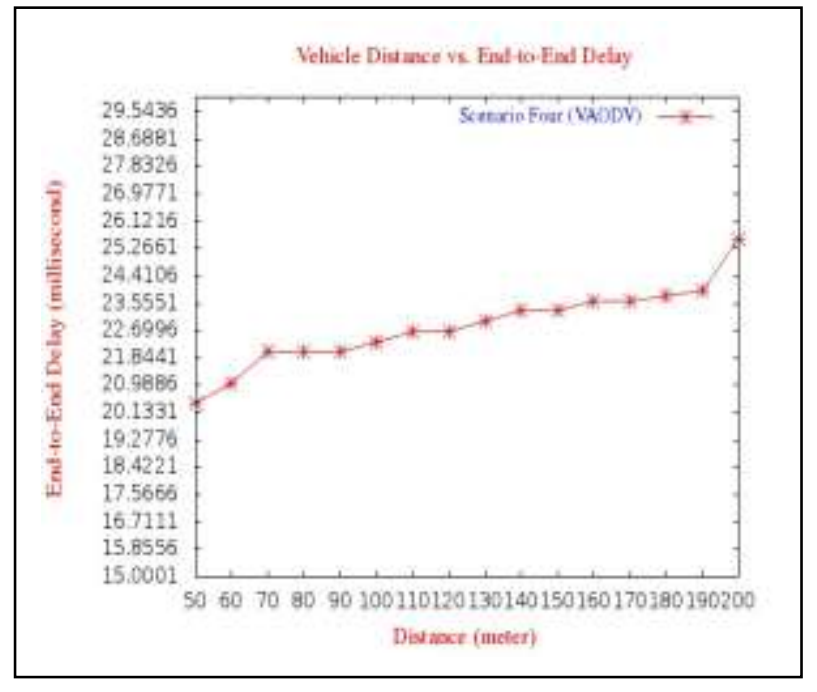

Fig. 26: Distance vs. End-to-End Delay for Scenario Four

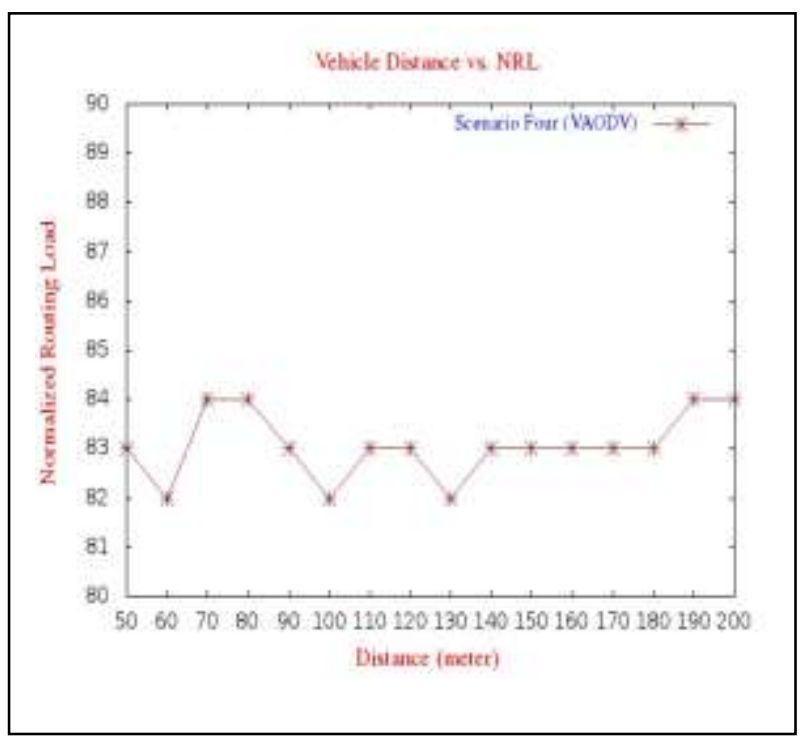

Fig. 27: Vehicle Distance vs. NRL for Scenario Four

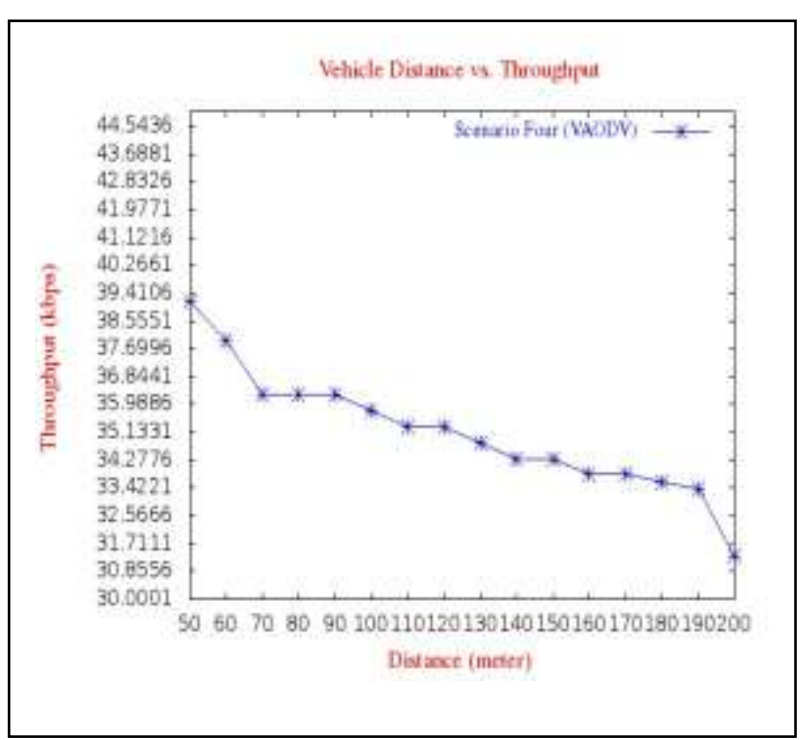

Fig. 28: Vehicle Distance vs. Throughput for Scenario Four 
International Journal of Computer Applications Technology and Research

Volume 4- Issue 10, 767 - 776, 2015, ISSN: 2319-8656

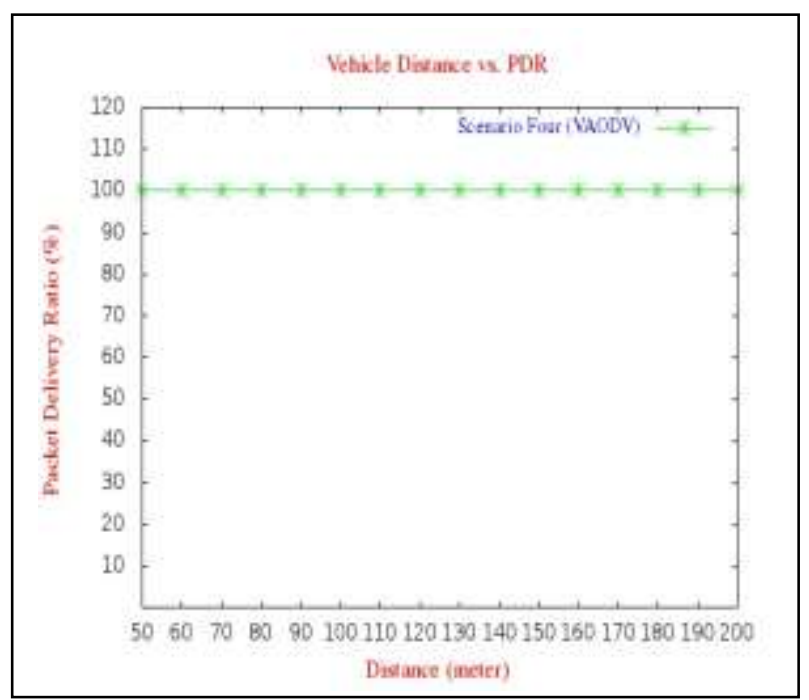

Fig. 29: Vehicle Distance vs. PDR for Scenario Four

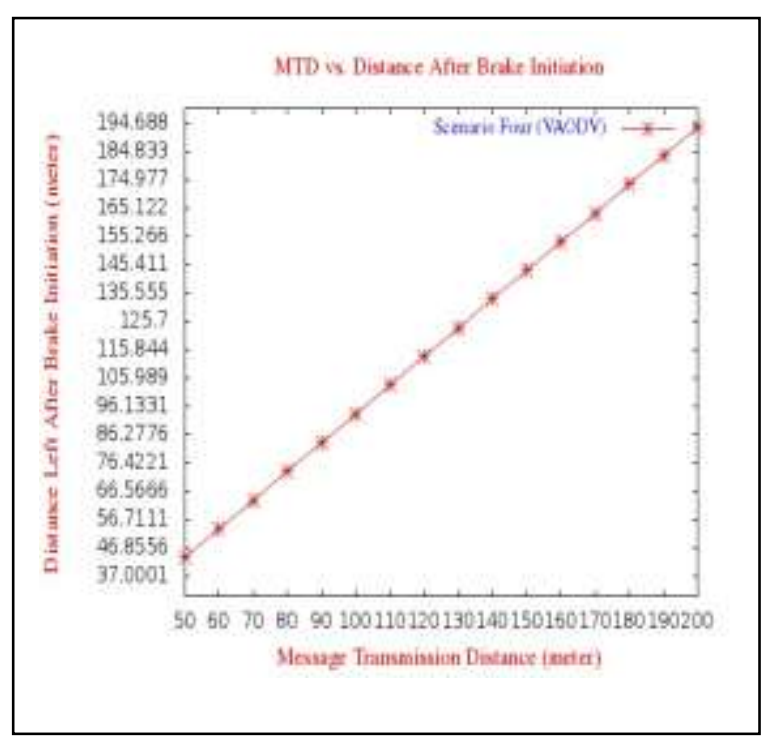

Fig. 30: MTD vs. Distance left for Scenario Four

In these figures Fig. 10-30 the End-to-End Delay, NRL, Throughput and PDR for four scenarios are calculated vs. vehicle distance means when the distance between any two vehicles is less than the warning distance the communication starts between these two vehicles and immediately the warning message sends. The warning distance is set as 50, 60, $70, \ldots$. . 200 meters. The above figure shows the value of the End-to-End Delay, NRL, Throughput and PDR for different warning distance. The parameter Distance Left after Brake Initiation is also calculated vs. vehicle distance and shown in above, which is very important for to find out at what particular distance the warning message needs to send for what particular speed.

In the figures Fig. 14, 19, 25 and 30 of Driver Reaction Time, the message processing time to give an alarm is not included because it assumes that the OBU unit has immediately given an alarm to the driver of the vehicle when the warning message came and also the driver responded immediately.

Let us say, the message processing time to give an alarm to the driver of the vehicle when the warning message came and driver thinking time is $1 \mathrm{sec}$. The results are shown in Fig. 3135 .

\section{Driver Reaction Time $=$ MRT + AT + DTT $+0.75 \quad$ Eq.7}

Where MRT is the Message Receive Time, AT is the time taken by the OBU to give an alarm and DTT is the Driver Thinking Time.

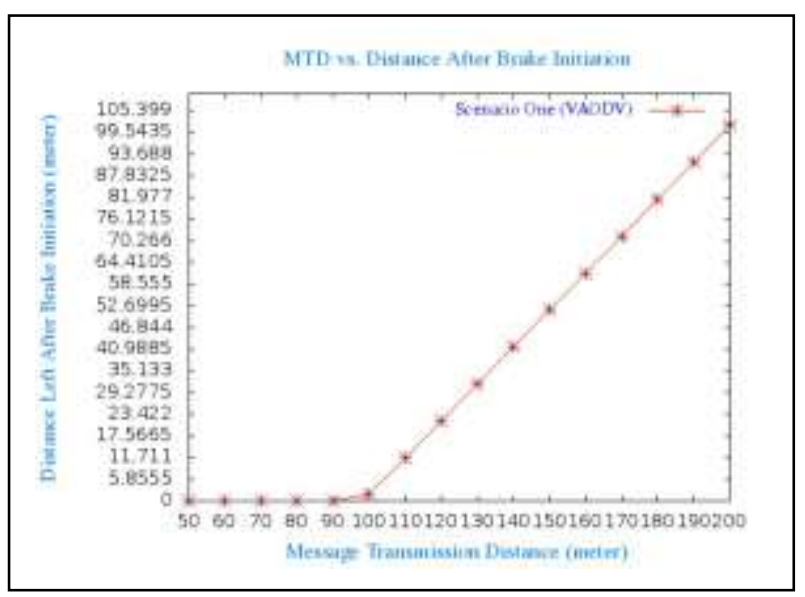

Fig. 31: MTD vs. Distance left for Scenario One

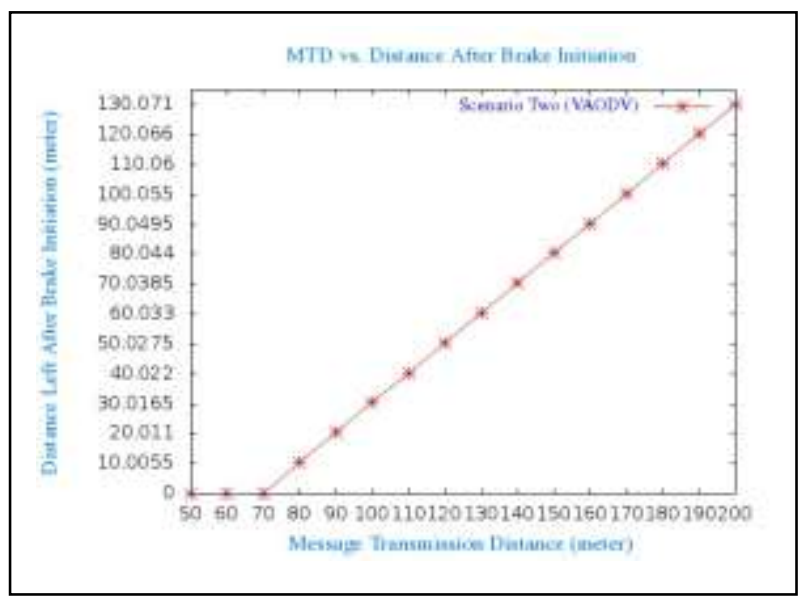

Fig. 32: MTD vs. Distance left for Scenario Two

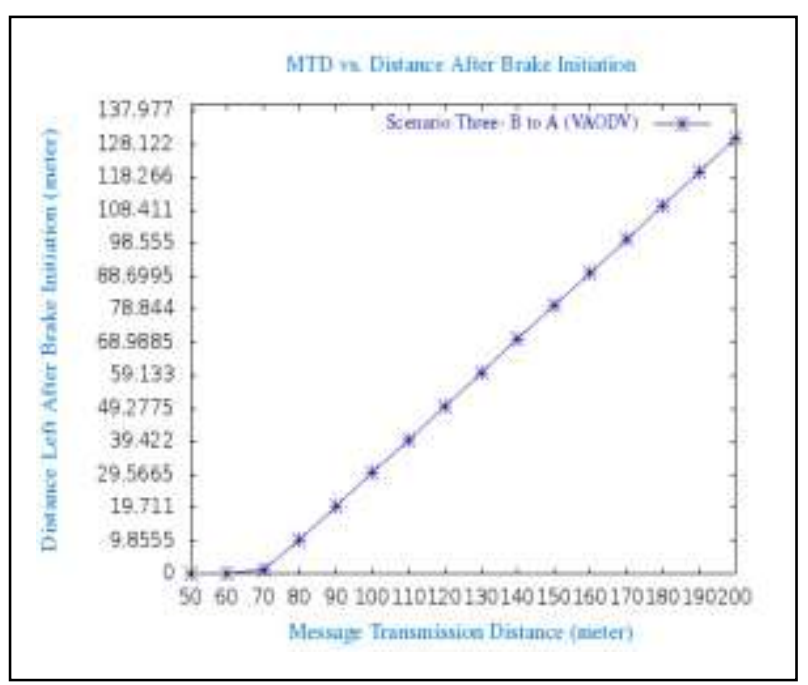

Fig. 33: MTD vs. Distance left in B to A for Scenario Three 


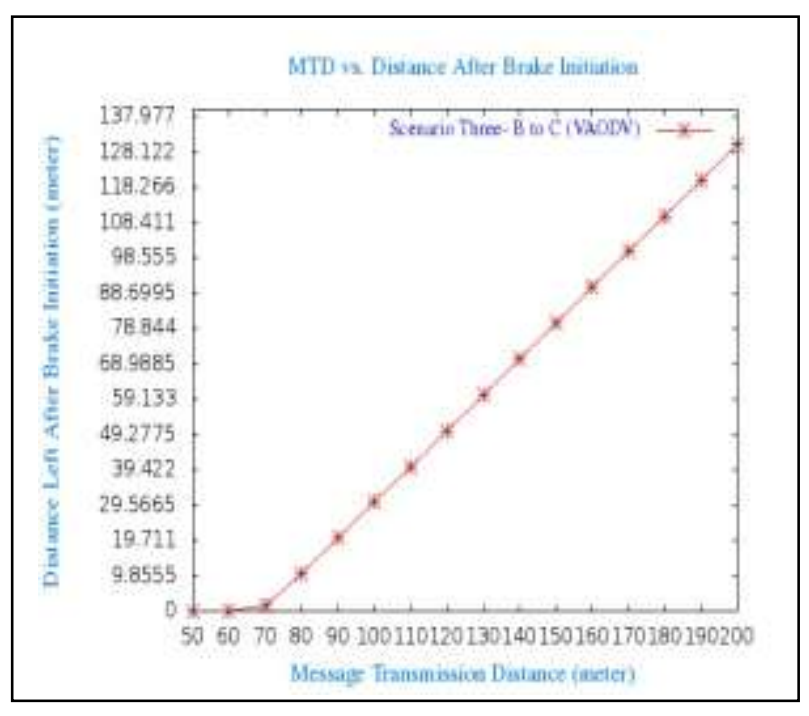

Fig. 34: MTD vs. Distance left in B to C for Scenario Three

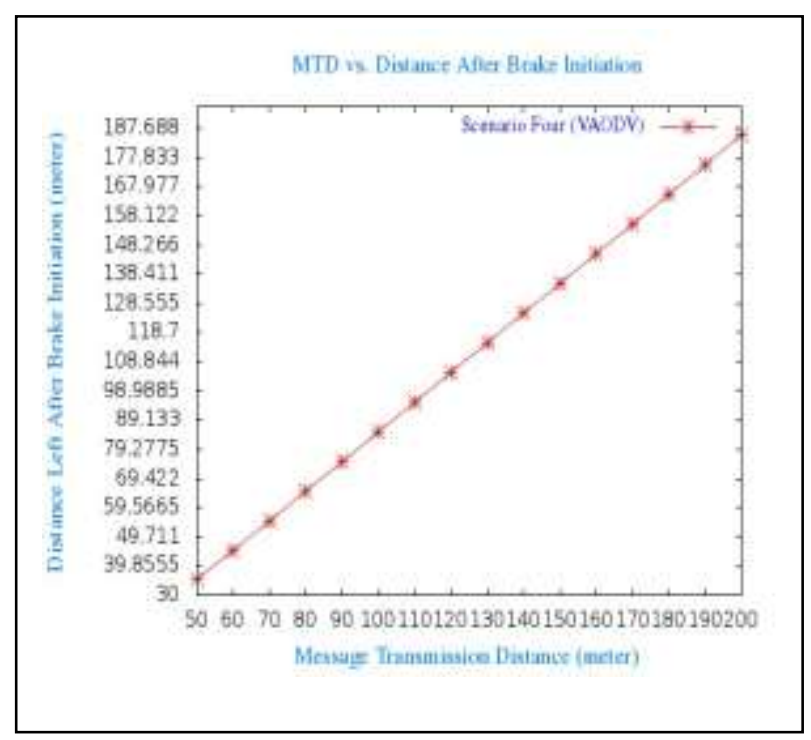

Fig. 35: MTD vs. Distance left for Scenario Four

The Table 2 contains the data of real world testing of vehicles [22].

Table 2: Braking Distance for speed of $100 \mathrm{~km} / \mathrm{h}$

\begin{tabular}{|c|c|}
\hline Model & Distance (meter) \\
\hline Alfa MITO & 37.61 \\
\hline Alfa Giulietta QV & 37.80 \\
\hline Audi A5 Sportback & 37.62 \\
\hline BMW 123D Hatch & 37.95 \\
\hline BMW 330D Coupe & 36.63 \\
\hline Chrysler 300C & 38.72 \\
\hline Holden VE Commodore SV6 & 39.86 \\
\hline HSV GXP & 37.76 \\
\hline HSV GTS (WP tuned - 2011) & 38.31 \\
\hline Nissan GTR (R35 - 2011) & 32.75 \\
\hline Porsche 911 Turbo S (2011) & 39.62 \\
\hline Renault Megane RS250 & 36.34 \\
\hline Renault RS Clio 200 & 36.43 \\
\hline Subaru Impreza WRX & 37.38 \\
\hline Suzuki Alto & 43.56 \\
\hline W Golf GTD & 37.58 \\
\hline
\end{tabular}

\begin{tabular}{|c|c|}
\hline VW Golf R & 39.57 \\
\hline VW Golf GTI & 39.36 \\
\hline Volvo C30 TS & 39.05 \\
\hline
\end{tabular}

The results of real world testing data propose that braking distance less than 40 meters needs by a car at a speed of $100 \mathrm{~km} / \mathrm{h}$.

The Table 3 contains the data given by the government [22].

Table 3: Braking Distance for speed of 0-180 km/h

\begin{tabular}{|c|c|}
\hline Speed (km/h) & Distance (meter) \\
\hline 0 & 0 \\
\hline 10 & 0 \\
\hline 20 & 3 \\
\hline 30 & 5 \\
\hline 40 & 9 \\
\hline 50 & 15 \\
\hline 60 & 21 \\
\hline 70 & 29 \\
\hline 80 & 38 \\
\hline 90 & 47 \\
\hline 100 & 60 \\
\hline 110 & 73 \\
\hline 120 & 86 \\
\hline 130 & 98 \\
\hline 140 & 110 \\
\hline 150 & 123 \\
\hline 160 & 136 \\
\hline 170 & 151 \\
\hline 180 & 166 \\
\hline
\end{tabular}

\section{CONCLUSION}

In this paper we have modified the AODV routing protocol named as VAODV which is used to simulate and also to analyze the VANETs. To find out the performance of the protocol the different parameters are calculated like End-toEnd Delay, NRL, Throughput and PDR vs. vehicle distance for four different scenarios. Our simulation result shows that in case of Scenario One where vehicles are at a speed of $100 \mathrm{~km} / \mathrm{h}$ moving towards each other, the braking distance 40 60 meters (Fig. 14) will be left if the warning message is sent at a warning distance or vehicle distance of 90-110 meters. In case of Scenario Two where vehicles are moving at a speed of $100 \mathrm{~km} / \mathrm{h}$, the braking distance $40-60$ meters (Fig. 19) will be left if the warning message is sent at a warning distance or vehicle distance of 80-100 meters. In case of Scenario Three where vehicles are moving at a speed of $100 \mathrm{~km} / \mathrm{h}$, the braking distance 40-60 meters (Fig. 24, 25) will be left if the warning message is sent at a warning distance or vehicle distance of 80-100 meters. In case of Scenario Four where vehicles are moving in the same direction, one is at a speed of $100 \mathrm{~km} / \mathrm{h}$ and another is at a speed of $70 \mathrm{~km} / \mathrm{h}$, the braking distance 40-60 meters (Fig. 30) will be left if the warning message is sent at a warning distance or vehicle distance of 50-70 meters.

\section{FUTURE WORK}

In the near future we plan to extend our work by giving more security to our VAODV protocol. We will also look into other factors like reliability by developing a trust based routing mechanism to track the misbehaving vehicles which is very important from the prospects of VANETs. 


\section{REFERENCES}

[1] A. Iyer, S. S. Kulkarni, V. Mhatre and C. P. Rosenberg, 2008, "A Taxonomy-based Approach to Design of Large-scale Sensor Networks", Springer, pp. 3-33.

[2] T. AL-Khdour and U. Baroudi, 2011, "Literature Review of MAC, Routing and Cross Layer Design Protocols for WSN", InTech, pp. 1-27.

[3] I. F. Akyildiz and I. H. Kasimoglu, 2004, "Wireless sensor and actor networks: research challenges", ELSEVIER Ad Hoc Networks, vol. 2, no. 4, pp. 351367.

[4] K. Sohraby, D. Minoli and T. Znati, 2007, "Wireless Sensor Networks: Technology, Protocols, and Applications",WILEY-INTERSCIENCE, vol. 1, pp. 1307.

[5] J. Liu, Z. Yang and I. Stojmenovic, 2013, "Receiver Consensus: On-Time Warning Delivery for Vehicular Ad-Hoc Networks", IEEE Transactions on Emerging Topics in Computing, vol. 1, no. 1, pp. 57-68.

[6] K. A. Hafeez, L. Zhao, B. Ma and J. W. Mark, 2013, "Performance Analysis and Enhancement of the DSRC for VANET's Safety Applications", IEEE Transactions on Vehicular Technology, vol. 62, no. 7, pp. 3069-3083.

[7] H. A. Omar, W. Zhuang, A. Abdrabou and L. Li, 2013, "Performance Evaluation of VeMAC Supporting Safety Applications in Vehicular Networks", IEEE Transactions on Emerging Topics in Computing, vol. 1, no. 1, pp. 6983.

[8] W. Ikram, S. Petersen, P. Orten and N. F. Thornhill, 2014, "Adaptive Multi-Channel Transmission Power Control for Industrial Wireless Instrumentation", IEEE Transactions on Industrial Informatics, vol. 10, no. 2, pp. 978-990.

[9] J. A. Gutierrez, M. Naeve, E. Callaway, M. Bourgeois, V. Mitter and B. Heile, 2001, "IEEE 802.15.4: a developing standard for low-power low-cost wireless personal area networks", IEEE Network, vol. 15, no. 5, pp. 12-19.

[10] Y. Huang, A. Pang and H. Hung, 2008, "An Adaptive GTS Allocation Scheme for IEEE 802.15.4", IEEE Transactions on Parallel and Distributed Systems, vol. 19 , no. 5, pp. 641-651

[11] Z. Shelby and C. Bormann, 2011, "6LoWPAN: The Wireless Embedded Internet”, John Wiley \& Sons, pp. 1244.
[12] C. K. Singh, A. Kumar and P. M. Ameer, 2008, "Performance evaluation of an IEEE 802.15.4 sensor network with a star topology", Springer Science \& Business Media, vol. 14, pp. 543-568.

[13] L. K. Bandyopadhyay, S. K. Chaulya and P. K. Mishra, 2009, "Wireless Communication in Underground Mines: RFID-based Sensor Networking", Springer Science \& Business Media, pp. 1-477.

[14] E. M. Royer and C. K. Toh, 1999, "A review of current routing protocols for ad hoc mobile wireless networks", IEEE Personal Communications, vol. 6, no. 2, pp. 46-55.

[15] X. H. Lin, Y. K. Kwok and V. K. N. Lau, 2005, "A quantitative comparison of ad hoc routing protocols with and without channel adaptation", IEEE Transactions on Mobile Computing, vol. 4, no. 2, pp. 111-128.

[16] C. E. Perkins, E. M. Royer, S. R. Das and M. K. Marina, 2001, "Performance comparison of two on-demand routing protocols for ad hoc networks", IEEE Personal Communications, vol. 8, no. 1, pp. 16-28.

[17] C. E. Perkins and E. M. Royer, 1999, "Ad-hoc ondemand distance vector routing", Second IEEE Workshop on Mobile Computing Systems and Applications, 1999. Proceedings. WMCSA '99, New Orleans, LA, pp. 90-100.

[18] J. H. Song, V. W. S. Wong and V. C. M. Leung, 2004 "Efficient on-demand routing for mobile ad hoc wireless access networks", IEEE Journal on Selected Areas in Communications, vol. 22, no. 7, pp. 1374-1383.

[19] T. Issariyakul and E. Hossain, 2011, "Introduction to Network Simulator NS2", Springer Science \& Business Media, vol. 2, pp. 1-536.

[20] L. Shrivastava, S. S. Bhadauraia, G. S. Tomar and B. K. Chaurasia, 2013, "Secure Congestion Adaptive Routing Using Group Signature Scheme", Springer Transactions on Computational Science XVII, vol. 7420, pp. 101-115.

[21] M. Green, 2000, "How long does it take to stop? Methodological analysis of driver perception-brake times", Transportation Human Factors, vol. 2, no. 3, pp. 195-216.

[22] Safe Drive Training [Online]. Available: http://www.sdt.com.au/safedrive-directorySTOPPINGDISTANCE.htm. 